\title{
Parenting Styles and Coping Strategies in PKU Early Detected Children
}

Journal of Inborn Errors of Metabolism \& Screening 2021, Volume 9: e20200014 DOI: https://doi.org/10.1590/2326-4594JIEMS-2020-0014

\section{María L. Pardo Campos ${ }^{1,2,3}$, Rosa Enacan ${ }^{1,2}$, Maria G. Valle ${ }^{1,2}$ and Ana Chiesa ${ }^{1,2}$ (D)}

\begin{abstract}
Phenylketonuria (PKU) requires tight control to prevent neurocognitive impairment but reports show that patients may present mild cognitive defects related to higher impulsivity. We hypothesize that chronic intervention may influence the parents and child bonding and the child's resources to face problems. To describe the PKU parenting styles perceived by the children (PS) and their coping strategies (CS) assessing their relationship with impulsivity, 30 early diagnosed and adequately treated PKU children and 30 non PKU aged-paired controls (CG) were compared. The Argentine Children's Coping Questionnaire, Argentine Scale Perception of the Relationship with Parents, WISC IV Comprehension Subtest, and CPT II test were administered. PKU PS were based on control: strict to pathologic in the mother and acceptable in the father (both $p<0.05$ vs. CG). Children significantly sought greater support and showed less emotional control when facing conflicts. These characteristics positively correlated with maternal control r:.383 and r:.398 (both $p<0.05)$. Impulsivity was higher in PKU $(p<0.05)$ but didn't associate with PS or CS. Maternal strict control wasn't linked to the higher impulsivity found (possibly neurobiologically based). Nevertheless, if both factors are present, patients may develop a psychological and/or behavioral trait of greater dependency and impulsivity that must be considered in their follow-up.
\end{abstract}

\section{Keywords}

Phenylketonuria, PKU, parenting styles, coping strategies.

\section{Introduction}

Phenylketonuria (PKU) is a chronic metabolic disease that needs to be treated and tightly controlled since it's neonatal detection to prevent neurocognitive impairment. This follows the WHO definition, which states that chronic diseases are conditions that lasting one year or more require ongoing medical attention and/or limit activities of daily living.[1] They include organic, psychological, and/or social diseases.

In the PKU scenario, the quality of life of the PKU child and his family may be affected and intrafamilial relationships may be compromised. So, it is important to recognize this burden and provide adequate guidance during follow up. [2,3]

On another note, coping strategies are defined as the resources that the individual uses to face conflictive situations with either cognitive and/or emotional effort. [4,5] In fact, how stressors are faced depends on the available personal resources, the environmental limitations to exert them, and the ability to put them into practice.[6-8]

It has been reported that chronically ill children may have fewer resources to solve everyday problems. Previous studies have stated that PKU patients may present mild cognitive deficits associated with the impact of the disease. Even with a normal IQ, cognitive deficiencies in executive functions have been consistently reported. [1,2] Among them, defects in the inhibitory impulse control and impaired cognitive flexibility were described. [1,3-5]

The aim of this paper was to characterize the parenting styles perceived by the PKU children and their predominant coping strategies, and to assess the relationship of these variables with impulsivity.

\footnotetext{
${ }^{1}$ Fundación de Endocrinología Infantil, Buenos Aires, Argentina.

${ }^{2}$ Hospital de Niños R Gutierrez, División de Endocrinología, Centro de Investigaciones Endocrinológicas “Dr. César Bergadá", Buenos Aires, Argentina. ${ }^{3}$ Universidad Católica Argentina, Facultad de Psicología y Psicopedagogia, Buenos Aires, Argentina.
}

Received september 19, 2020, and in revised form december 10, 2020. Accepted for publication february 18, 2021.

\section{Corresponding Author:}

María Laura Pardo Campos, Fundación de Endocrinología Infantil, Buenos Aires, Argentina.

Email:mlpardocampos@gmail.com 


\section{Research Design}

We conducted a descriptive, comparative study with an ex post facto, cross-sectional, and prospective design. PKU patients aged from 8.0 to 11 years were recruited among a hundred case population treated at our PKU clinic in Buenos Aires, Argentina. They were compared with an aged-paired control group (CG) of healthy children. The inclusion criteria for PKU patients were: a) PKU diagnosis within the first 30 days of life, b) have been treated early and adequately since detection, c) good and regular compliance with medical and biochemical controls, d) without a concurrent chronic disease, e) attending public or private single shift schools located in the Buenos Aires Autonomous City or Buenos Aires Province, and e) minimum complete secondary school parental level of education.

The CG was as well recruited from public or private schools located in the Buenos Aires Autonomous City or Buenos Aires Province considering the applicable items of the same inclusion criteria. For them, school authorities approved their participation in advance, and parents' consent was provided. Both groups made up a non-probabilistic accidental sample that was selected 2017. Data were collected between 2018 and 2019.

All children were assessed using the Argentine Scale for the Perception of Parent Relations for children aged 8 to 12 years, the Argentine Coping Questionnaire for children aged 8 to 12 years. [6-8] The Comprehension Subtest of the Wechsler Intelligence Scale for Children IV (WISC IV) was used to assess the comprehension of strategies to solve situations of daily living implying practical social judgment, and the Conners Continuous Performance Test II (CPT II) (stimulus cancellation tasks with different presentation times) was implemented to test impulsivity $\cdot[9,10]$

The scales and the subtest were administered during an individual outpatient interview. Individual results were delivered in written during a feedback interview in which the relevant guidelines were provided.

The study was approved by the Research and Teaching Committee and Ethics Committee of the Buenos Aires Children's Hospital Ricardo Gutiérrez and written informed consent for study participation was obtained from the parents of the studied children. Children also provided oral consent.
Statistical analysis. The sample size of PKU children to be studied was estimated at 30 children (level of confidence: $95 \%$; absolute accuracy: $5 \%$ on both sides).[11]

Multivariate Analysis of Variance (MANOVA) was used to compare parental styles and coping strategies in both groups while Student's t-test for independent samples were used to assess differences in their cognitive impulsivity. Pearson's correlation was used for stating the relation between impulsivity and parental styles, and coping strategies. Finally, the effect size was analyzed for all results using the partial Eta squared $\left(\eta p^{2}\right)$. In all the analyses, conventional confidence levels of $95 \%$ were used to test the hypotheses ( $\mathrm{p}$-value $<0.05)$.

\section{Results}

30 children were selected for each group. All of them had good academic performance according to chronological age. Table 1 shows the characteristics of the PKU children (12 girls and 18 boys) as well as the parameters of dietary phenylalanine tolerance, early treatment and good adherence.

The parental style profile found in both groups is shown in Table 2. The PKU children showed a statistically significant difference with CG in the perception of the relationship with their mother $(\mathrm{p}<.001)$ with a low magnitude of the effect $\left(\eta \mathrm{p}^{2}=.158\right)$. This relationship was perceived based on strict and pathologic control.

Regarding the relationship with their fathers, PKU children also differed significantly from the CG children in their perception, with low size effect $\left(\mathrm{p}<.004\right.$ and $\left.\eta \mathrm{p}^{2}=.141\right)$. This relationship was based on acceptable control.

Table 3 shows the coping strategies found in both groups and their differences. In general, coping strategies differed significantly between groups with a high effect size (Hotelling's F $(9,50)=$ 8,$\left.735 ; \mathrm{p}<.001 ; \eta \mathrm{p}^{2}=.611\right)$. When facing conflicting situations, PKU children sought more support and exhibited less emotional control than the CG ( $\mathrm{p}<.004$ and $\mathrm{p}<.001$, respectively). Both strategies positively and significantly correlated with maternal control ( $\mathrm{r}: .383$ and $\mathrm{r}$ : .398, both $\mathrm{p}<0.05$ ).

The results in the comprehension subtest of the Wechsler Intelligence Scale for Children IV (WISC IV) did not show a significant correlation that showed fewer resources of the PKU group to solve tasks that involve social judgment when compared to the CG. (p.09).

Table 1. Initial and follow up characteristics of the 30 studied PKU children. (Median (range)).

\begin{tabular}{lc}
\hline Age at diagnosis (days) & $18(11-30)$ \\
Phenylalanine at diagnosis (mg/dl) & $20(11-33)$ \\
Phenylalanine tolerance. (mg/day) & $350(290-500)$ \\
Age at evaluation (years) & $10.4(8.5-11.8)$ \\
Phenylalanine blood levels in the first year (mg/dl) & $3.56(1.5-5.9)$ \\
Phenylalanine blood levels from 2 to 5 years of age (mg/dl) & $3.60(1.8-7)$ \\
Phenylalanine blood levels from 6 years of age to evaluation (mg/dl) & $3.6(1.8-6)$ \\
Phenylalanine levels at evaluation (mg/dl) & $4.6(1.4-7.3)$ \\
\% of recommended Phenylalanine blood controls performed the year previous to evaluation & $75 \%(50-100 \%)$
\end{tabular}


Table 2. Parental styles found in the studied PKU children vs. control group (CG).

\begin{tabular}{|c|c|c|c|c|c|c|}
\hline \multirow[t]{2}{*}{ Parental relationship perception } & \multicolumn{2}{|c|}{$\begin{array}{c}\text { PKU } \\
(n=30)\end{array}$} & \multicolumn{2}{|c|}{$\underset{(n=30)}{\mathbf{C G}}$} & \multirow[b]{2}{*}{$F(5,54)$} & \multirow[b]{2}{*}{$P$} \\
\hline & Mean & SD & Mean & SD & & \\
\hline Maternal level of acceptance & 2.52 & .29 & 2.02 & .53 & 2.58 & .194 \\
\hline Acceptable maternal control & 2.14 & .30 & 2.23 & .35 & 1.05 & .298 \\
\hline Strict maternal control & 2.58 & .30 & 2.13 & .37 & 3.87 & $.049 *$ \\
\hline Pathological maternal control & 2.15 & 62 & 1.62 & .44 & 1.01 & $.001 *$ \\
\hline Extreme independence from the mother & 1.55 & .39 & 1.68 & .46 & 1,32 & .255 \\
\hline Paternal level of acceptance & 2.44 & .42 & 2.12 & .27 & 1.22 & .273 \\
\hline Acceptable paternal control & 2.12 & .38 & 2.30 & .27 & 4.05 & $.049 *$ \\
\hline Strict paternal control & 1.85 & .44 & 1.97 & .32 & 1.45 & .233 \\
\hline Pathological paternal control & 2.05 & .24 & 2.07 & .23 & .068 & .366 \\
\hline Extreme independence from the father & 2.01 & .24 & 2.01 & .20 & 3. 52 & .066 \\
\hline
\end{tabular}

Table 3. Coping strategies found in the 30 studied PKU children vs the control group (CG).

\begin{tabular}{|c|c|c|c|c|c|c|}
\hline \multirow[t]{3}{*}{ General strategies } & \multicolumn{2}{|c|}{ Hotelling's F } & \multicolumn{2}{|c|}{$(9,50)=8,735$} & \multirow[t]{2}{*}{$<\mathrm{p}: .0001$} & \multirow[t]{2}{*}{$\eta P^{2}=.611$} \\
\hline & \multicolumn{2}{|c|}{$\begin{array}{c}\text { PKU } \\
(n=30)\end{array}$} & \multicolumn{2}{|c|}{$\begin{array}{c}C G \\
(n=30)\end{array}$} & & \\
\hline & Mean & SD & Mean & SD & & \\
\hline Logical analysis & 2.01 & .68 & 2.38 & .43 & 3.45 & .11 \\
\hline Cognitive restructuring & 1.82 & .54 & 2.56 & .36 & .20 & .40 \\
\hline Cognitive avoidance & 2.08 & .78 & 2.06 & .54 & 2.80 & .91 \\
\hline Seeking alternative rewards & 1.47 & .73 & 1.97 & .47 & 3.10 & .17 \\
\hline Emotional control & 1.52 & .58 & 2.12 & .53 & 1.04 & $.001 *$ \\
\hline Paralisation & 1.42 & .60 & 1.84 & .47 & 8.43 & 1.22 \\
\hline Acting on the problem & 2.01 & .67 & 2.35 & .47 & .373 & .54 \\
\hline
\end{tabular}

${ }^{*} \mathrm{p}<.05$ vs CG ,SD: Standard deviation, F: significance F-test (value)

In CPT II PKU children made significantly more impulsive errors $(\mathrm{p}<.001)$ with a moderate size effect $\left(\eta p^{2}=.30\right)$. Nevertheless, the association of impulsivity with parental styles or coping strategies was not statistically significant.

\section{Discussion}

This study aimed to investigate the impact of the PKU chronic condition on the parenting styles perceived by the affected children and their coping strategies. Not only the available published evidence in this subject is scarce, but also the findings can contribute to the treatment and follow up of PKU families

Our results confirm that the impact of PKU on family dynamics and child bonding is crucial. PKU constitutes a good example of the need of permanent efforts to reach the recommended biochemical goals. Everyday care demands an adequate diet which relies on level of confidence between the parents and child.
Previous reports point out the increased risk of overprotection of the chronically ill child, resulting in a highly controlled relationship. Moreover, the acknowledgment of the presence of a latent disease in the well-treated and followed-up patients is relevant in the parents' attitude. Although the clinical evidence of harm does not exist, the fear of the unknown and future consequences remains, which may be reflected in greater controlling attitudes.

The first family bond interacts with the dispositions of the child very early in life. Thus, the interpersonal relationships rely on the children's ability to face difficulties, and the selfconfidence and security they experience to solve them.

Parental styles perceived by the child range from acceptance to negligence. Acceptance of individuation leads to positive involvement and, together with parental control, builds up the parental style that the child perceives. This control may, in turn, range from acceptable to strict or even pathological. Strictness implies control with demand and anxiety while 
pathological control encompasses greater hostility, anxiety, and control through guilt. Moreover, parents may face the child's disease differently depending on their personalities, previous experiences, fears, and anxiety.

In our cohort, the father relationship was perceived as acceptable controlling. This style is characterized by warmth and strictness and leads to a closer relationship with the child. These findings agree with our previous observations in fathers of early detected and treated congenital hypothyroid children, who presented more proximity with their sick children compared to controls. [12] Moreover, acceptable control has been recently described as key in the internalization of social values and self-esteem in PKU children and adolescents of different cultures.[13]

On the other hand, the maternal style perceived by our PKU children was of strict/pathological control. While acceptance with accepted to strict control would be within a democratic (healthy) link, strict to pathological control, can become harmful, negatively influencing the development of the child.

When a PKU child is diagnosed, parents must assume immediate responsibility for his management and prevention of neurological damage. They must supervise the child's nutritional intake, ongoing medical appointments, and regular blood tests.

Recently, Carpenter et al. explored the experiences of parents of children with PKU under the age of two with an interpretative phenomenological analysis. The parents interviewed pointed out that control, striving for normality, and acceptance of PKU were the main themes to confront diagnosis. They reported as well significant stressors as the persistence of guilty feelings for passing down a genetic disorder and the impression that they were expected to adapt and cope from the beginning disregarding their emotions.[14]

The maternal style found in our cohort may be related with the closest responsibility for diet as PKU mothers have been recognized to be more vigorous than fathers in monitoring the child's diet prescription. [15]

Psychological adjustment of the parents and their difficulties to accept the disease and treatment may also influence the child's coping strategies $[3,16,17]$ As the child grows, the daily effort sometimes overwhelms the mother, and her strictness may impair the child's abilities to face new situations.

When facing problems, our PKU group needed more support and reacted with less emotional control in the regulation of their behavior than controls. Nevertheless, WISC IV did not find in the PKU group fewer resources to solve tasks that involve social judgment compared to the CG. Although the sample size was adequate for our evaluation, more extensive studies are needed to confirm our findings.

Our PKU children made more mistakes when executing tasks than the CG, which reflects higher impulsiveness. Nevertheless, this was not significantly associated with parental styles or coping strategies.
High impulsiveness, one of the factors that may influence emotional control, can result from a compulsive behavior without emotional control searching relief from tension/stress, or be the consequence of the lack of planned execution that leads to a faster but wrong response.

The neurobiological background of the disease, and its already reported dopaminergic impairment, would be a possible explanation for the higher impulsivity found in our PKU group. [18]

Nevertheless, the high controlling parenting style influencing the biologically dysregulated emotional control may develop in a psychological and/or behavioral trait of greater dependency and impulsivity.

Our observations are important in the follow up of PKU patients. Parenting styles are constructed along the children's life with the parent's resources, fears, and experiences, and the child's perception gives a clue to investigate distinct aspects of the family interaction.

Recognized patterns could be brought out and applied to the clinical ground to ameliorate the impact of pathologic bonding. Continuous communication with PKU families will become the best tool to identify such risks and build a healthy emotional space in which PKU children and adolescents can grow and develop.

\section{Funding}

This research received no specific grant from any funding agency in the public, commercial, or not-for-profit sectors. A Chiesa is a research member of the Carrera de Investigador en Salud, del Gobierno de la Ciudad Autónoma de Buenos Aires. R Enacan and MG Valle are a research fellows of the Ministerio de Salud, Gobierno de la Ciudad Autónoma de Buenos Aires.

\section{Declaration of Conflicting Interests}

None declared.

\section{References}

1. CIE-10. Décima revisión de la Clasificación Internacional de las Enfermedades. Madrid: Editorial Meditor; 1992.

2. Zimmerman Tansella C. Factores psicosociales en las enfermedades crónicas en la infancia. In: J RodriguezSacristan, ed. Psicopatología del niño y del adolescente. Sevilla, Spain: Universidad de Sevilla; 1995:1089-1103.

3. Chao MC, Yang P, Hsu H, Yong YJ. Follow-up study of behavioral development and parenting stress profiles in children with congenital hypothyroidism. Kaohsiung J Med Sci. 2009;25(11):588-595. doi: 10.1016/S1607551X(09)70561-3

4. Chiovato L, Bargagna S. Congenital hypothyroidism: treat children but don't forget their parents. Eur J Endocrinol. 1999;14:101-104. doi: 10.1530/eje.0.1410101 
5. Lazarus R, Folkman S. Estrés y procesos cognitivos. Barcelona, Spain: Ediciones Martínez Roca; 1986

6. Richaud de Minzi MC. Evaluación del afrontamiento en niños de 8 a 12 años. Rev Mejicana Psi. 2006; 23(1): 63-81.

7. Richaud Minzi MC. Inventario acerca de la percepción que tienen los Niños y las Niñas de las Relaciones con sus Padres y Madres. Versión para 4 a 6 años. Rev Interam Psic. 2002;36(1-2):149-165.

8. Richau Minzi MC. La percepción de etilos de relación con sus padres y madre en niños y niñas de 8 a 12 años. Rev Iberoamericana Diag Eval Psi. 2007;23(1): 68-81

9. Wechsler D. Test de Inteligencia para Niños WISC-III. Manual. Buenos Aires. Argentina: Paidós; 1997

10. Conners CK. Conners Continuous Performance Test Computer Program 3.0 User's Manual. Toronto, Canada: Multi-Health Systems; 1994.

11. Lwanga SK, Lemeshow S. Determinación del tamaño de las muestras en los estudios sanitarios: manual práctico. Geneva. Switzerland: World Health Organization; 1991.

12. Pardo Campos ML, Musso M, Keselman A, et al. Parenting styles and coping strategies among patients with early detected and treated congenital hypothyroidism. Arch Argent Pediatr. 2018;116(2):142-153.
13. Martinez I, Fernando Garcia F, Veiga F, et al. Parenting Styles, Internalization of Values and Self-Esteem: A Cross-Cultural Study in Spain, Portugal and Brazil. Int J Environ Res Public Health. 2020;17(7):2370. doi: 10.3390/ ijerph 17072370

14. Carpenter K, Wittkowski A, Hare DJ, et al. Parenting a Child with Phenylketonuria (PKU): Interpretative. Phenomenological Analysis (IPA) of the Experience of Parents. J Genet Couns. 2018;27:1074-1086 doi: 10.1007/ s10897-018-0227-7U

15. Antshel K, Brewster S, Waisbren SE. Child and parent attributions in chronic pediatric conditions: phenylketonuria (PKU) as an exemplar. J Child Psychol Psyc. 2004; 45(3): 622-630 doi: 10.1111/j.1469-7610.2004.00251

16. Luque Parra DJ. Alumnado con trastorno crónico. Elementos para una intervención educativa. Malága, Spain: Universidad de Málaga; 2007

17. Boekaerts S, Roder L. Stress, Coping, and adjustment in children with a chronic disease: a review of the literature. Disabil Rehabil. 1999;21(7):311-37. doi: 10.1080/09638 2899297576

18. Boot E, Hollak CEM, Huijbregts SCJ, et al. Cerebral dopamine deficiency, plasma monoamine alterations and neurocognitive deficits in adults with phenylketonuria Psychol Med. 2017;47(16):2854-2865. doi: 10.1017/S003 3291717001398 